\title{
Comparative Effect of Different Combinations of Animal Manures and Humic acid on selected soil biochemical properties
}

\author{
Abdelbagi Mohamed Elnour, Mehmet Burak TAȘKIN, Sonay SÖZÜDOĞRU \\ OK
}

Department of Soil Science and Plant Nutrition, Faculty of Agriculture, Ankara University, Turkey

Email: soils star39@hotmail.com / mohamedali@ankara.edu.tr

\begin{abstract}
The main objectives of this study were to evaluate the effect of animal manures combinations and humic acid on some soil biochemical properties. The laboratory incubation experiment was conducted using a completely randomized design with three replicates. The animal manures included chicken manure (ChM) and cow manure (CoM). The treatments of humic acid (HA), chicken manure (ChM) and cow manure (CoM) were applied on clay soil at a rate of $10 \mathrm{t}$. ha-1. The treatments used were: Control (T1), HA (T2), HA + ChM (T3) and $H A+C o M(T 4)$. The soil samples were incubated for 15 , 30, 45 and 60 days at $28{ }^{\circ} \mathrm{C}$ and was analyzed for soil $\mathrm{pH}$, the electrical conductivity (EC), total nitrogen, available phosphorus, potassium content, soil organic carbon percentages (SOC) and soil respiration (CO2). In general, the results showed a significant difference between all treatments and the control. Also, the applications of treatments have lowered the soil $\mathrm{pH}$ and significant increase in EC was observed as days of incubation. While, the $N, P, K, S O C$ and soil respiration (CO2) were significant increased and reached its peak at 45 days of incubation and decreased thereafter with time. The results showed that applications of organic matter had significant effect on soil biochemical properties and treatment $4 \mathrm{T4}(\mathrm{HA}+\mathrm{CoM})$ showed a significant superiority compare with other treatments.
\end{abstract}

Keywords- Animal Manures, Humic acid, soil respiration, soil chemical Properties.

\section{INTRODUCTION}

The addition of organic materials has the aim to improve soil fertility and increase agricultural production. When applied for a long time can impair certain soil properties. The mineralization of organic matter application into soils increases nutrient contents such as nitrogen, phosphorus, sulfur and smaller amount of micronutrients [1], but also increase soil acidity- $\mathrm{pH}$ [2], and there has been increasing of soil salinity [3]. The humic matter is formed through the chemical and biological humification of plant and animal matter and through the biological activities of microorganisms. Humic acids (HAs) are the main fractions of humic substances (HS) and it plays a vital role in soil fertility and plant nutrition. The addition of humic acid (HAs) into the soil can affect some soil properties such as enrichment in soil nutrients, an increase of microbial population, enzyme activities, higher cation exchange capacity (CEC), and improvement of soil structure [4]. Incorporation of HAs into soils stimulated root growth, branching and initiation of root hairs and could partially be attributed to enhanced nutrient uptake [5]. Animal manures (such as chicken and cow manures) can be potentially beneficial for soil properties [6]. The organic manures are excellent fertilizers for the plant, because of the beneficial effects of releasing nutrients to the soil upon their decomposition periods such as nitrogen, phosphorus, potassium and a smaller amount of micronutrients. They can be considered an excellent source of combinations of nutrients [7].

\subsection{Objective}

The objective of the study was to determine the effect of the combination of humic acid; chicken manure and cow manure on some soil biochemical properties.

\section{MATERIALS AND METHODS}

2.1 Soil, treatments and experimental design The soil used in this study was taken from Ankara University - faculty of agriculture -Soil Science research field at depth of $0-30 \mathrm{~cm}$. The soil was classified as aridisol based on Soil Taxonomy [8]. Humic acids was added to soil as powder and brought from Ankara, Turkey. The chicken manure and cow manure were applied to soil after fermentation for 6 months. The combinations of these materials were prepared and mixed with soil on oven dry weight basis at a rate of 10 ton/ha. A laboratory incubation experiment was carried out in 
complete randomize design (CRD) with three replicates in four different incubation periods (15, 30, 45 and 60 day). The soil weight was $100 \mathrm{~g}$ air dry in plastic containers. The treatments were as follows: T1: Control (no addition); T2: Humic acid (10 ton/ha); T3: humic acid (5 ton/ha) + chicken manure $(5$ ton/ha); T4: humic acid $(5$ ton/ha) + cow manure ( 5 ton/ha). The soil samples were incubated at $28{ }^{\circ} \mathrm{C}$. The soil moisture was kept at field capacity condition $(34.33 \%)$ by using distilled water. At the end of each incubation period soil samples were collected.

\subsection{Soil analyses:}

Soil samples were air-dried, ground and passed through a $2 \mathrm{~mm}$ sieve prior to chemical analysis. Soil EC and $\mathrm{pH}$ were extracted with 1:5 soil: water ratio and measured potentiometrically using EC-meter (Model JENWAY 4510 date of Mani: Sep, 05 serial No 01892) and glass pH meter electrodes (Model JENWAY 3510 date of Manf. Jan, 09 serial No 05864), respectively, [9]. The total N, phosphorus, and potassium content were determined according to the methods described by [10]. Organic carbon (OC) content was determined by Walkley-Black method [11]. The soil respiration (CO2) was calculated as $\mathrm{ml} \mathrm{CO} 2 / \mathrm{kg} / \mathrm{hr}$ [12-13].

\subsection{Soil analyses}

Statistical analysis for means comparison was performed using Tukey's test in SAS version 9 [14].

\section{RESULTS AND DISCUSSION}

\subsection{Soil use of study}

The data presented in Table (1) showed some biochemical analysis of the soil used in this study. The soil was moderately alkaline, the electrical conductivity (EC) was $0.341(\mathrm{dS} / \mathrm{m})$ classified as non-saline.

Table.1: Some biochemical properties of soil used in this

\begin{tabular}{|c|c|c|c|c|c|c|c|}
\hline $\begin{array}{c}\text { Materi } \\
\text { als }\end{array}$ & $\mathrm{pH}$ & $\begin{array}{c}\mathrm{EC} \\
(\mathrm{dS} /\end{array}$ & $\begin{array}{c}\mathrm{N} \\
(\%)\end{array}$ & $\begin{array}{c}\mathrm{P} \\
(\%)\end{array}$ & $\begin{array}{c}\mathrm{K} \\
(\%)\end{array}$ & $\begin{array}{c}\mathrm{O} . \\
\mathrm{C} \\
(\%)\end{array}$ & $\begin{array}{c}\mathrm{CO}_{2} \\
(\mathrm{mg} \\
\left.\mathrm{kg}^{-1}\right)\end{array}$ \\
\hline Soil & 8.1 & 0.34 & 0.08 & 3.4 & 37. & 0.8 & 78.8 \\
& 5 & 1 & 8 & 8 & 2 & 9 & \\
\hline
\end{tabular}

\subsection{Soil pH}

Significant differences were observed in the soil $\mathrm{pH}$ between the control and all of the treatments throughout the incubation period. The control treatment (T1) was the highest (8.29) and treatment T3 (HA + CHM) was the lowest (7.88). That is because the decomposed organic matter released organic acids that lowered the $\mathrm{pH}$. Regardless of organic matter, soil $\mathrm{pH}$ gradually decreased with the increase of incubation time (Fig. 1). Generally, treatment $\mathrm{T} 3(\mathrm{HA}+\mathrm{ChM})$ was slightly acidic compared with other treatments. These results are in line with [1516], who showed that $\mathrm{pH}$ of cow manure is significantly greater than chicken manure treatment.

\subsection{Electrical conductivity (EC)}

The results indicated that the treatments significantly affected the electrical conductivity (EC) compared to the control. The control treatment (T1) was the lowest $(0.340$ $\mathrm{dSm1}-)$ and treatment $\mathrm{T} 3(\mathrm{HA}+\mathrm{ChM})$ was the highest (0.442 dSm1-) (Fig. 2). Generally, soil EC increased significantly with incubation time and reached its peak at 45 days. At 60 days of incubation soil, EC was decreased. In general, the result showed, treatment T4 (HA + CoM) was the best $(0.401 \mathrm{dSm1-})$ compared with other treatments. This could be explained by the fact that the application of a combination of humic acid and cow manure will improve the physical condition of the soil that facilitate the water movement and hence salt leaching. Similar results were obtained by [17-18] who showed that the EC significantly increases with the application of chicken, cow manures and the potential of manure-induced soil salinization was very high in chicken manure compared with cow manure. This is may be due to the concentrations of nutrients released after decomposition.

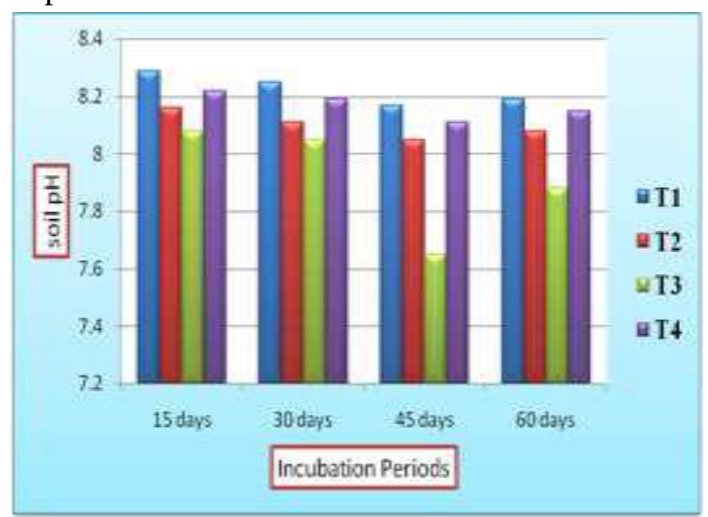

Fig.1: Effect of treatments on soil pH

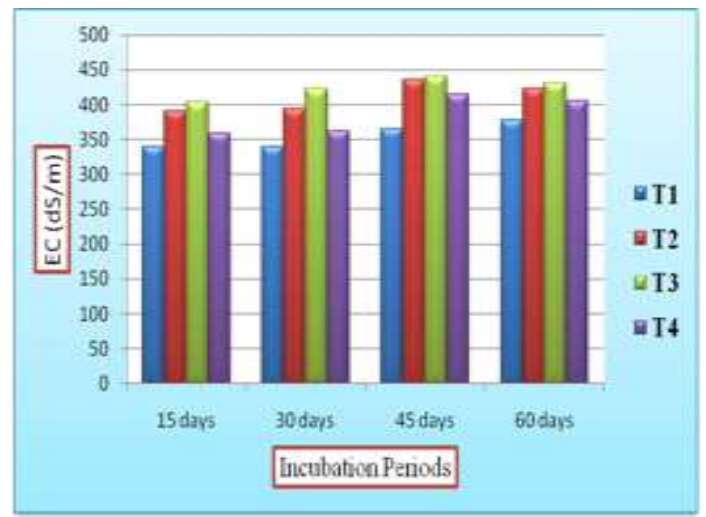

Fig.2: Effect of treatments on electrical conductivity(EC) 


\subsection{Total nitrogen $(\mathrm{N})$}

The soil nitrogen content showed a significant increase by treatments compared with the control. The values of total $\mathrm{N}$ ranged from $(0.101 \mathrm{mg} \mathrm{kg} 1-)$ in control $\mathrm{T} 1$ to $(0.215$ $\mathrm{mg} \mathrm{kg} 1-)$ in treatment $\mathrm{T} 3(\mathrm{HA}+\mathrm{ChM})$. This is natural because applications of manure release nitrogen upon decomposition. Generally, soil nitrogen content was increased significantly with incubation time and reached its peak at 45 days. But in the case of treatment T2 (HA), it was observed that the total nitrogen decreased from (0.162 $\mathrm{mg} \mathrm{kg1-)}$ at 30 days to (0.134 $\mathrm{mg} \mathrm{kg1-)}$ at 60 days of the incubation period (Fig. 3). It was observed that treatment $\mathrm{T} 3(\mathrm{HA}+\mathrm{ChM})$ was higher compared with treatment $\mathrm{T} 4(\mathrm{HA}+\mathrm{CoM})$. However, treatment $\mathrm{T} 4(\mathrm{HA}+$ CoM) was the best treatment compared with the other treatments, that is because there was no significant difference between 45 and 60 days of incubation time. [19], who found that organic manure increases total $\mathrm{N}$.

\subsection{Phosphorus (\%)}

The analysis of variance showed significant effects on phosphorous content by all treatments during the incubation time. The control treatment $\mathrm{T} 1$ was the lowest $(3.65 \%)$ and treatment $\mathrm{T} 4(\mathrm{HA}+\mathrm{CoM})$ was the highest (14.64\%). In general, the phosphorus content was increased by incubation time and reached its peak at 45 days. The value of $\mathrm{P}$ was found to be $6.5 \%$ in T2 (HA), while in treatment $\mathrm{T} 3(\mathrm{HA}+\mathrm{ChM})$ the value was $12.54 \%$ (Fig. 4). Treatment $\mathrm{T} 4(\mathrm{HA}+\mathrm{CoM})$ was the best compared with others treatments. That is because the decomposed cow manure released more organic acids and that lowers the $\mathrm{pH}$. Therefore, the decrease in soil $\mathrm{pH}$ will lead to an increase in phosphorus availability. Similar results were obtained by [20] who found that application of manure or compost increased the phosphorus content of the soil.

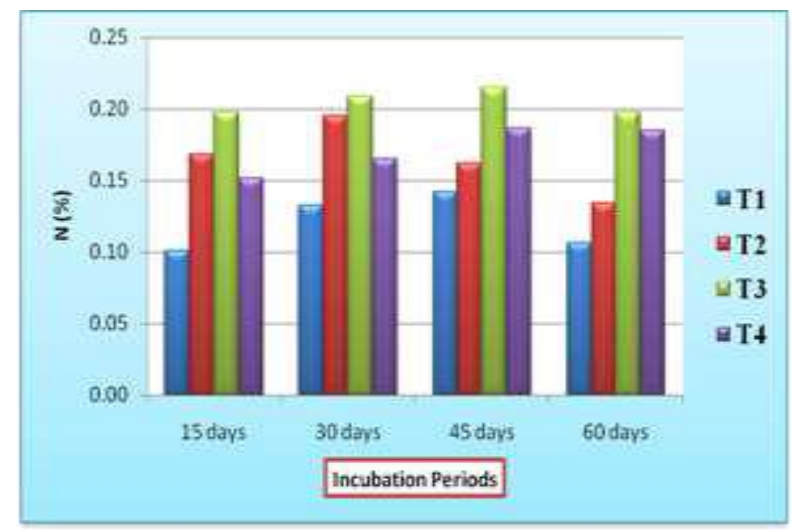

Fig.3: Effect of treatments on total nitrogen (\%)

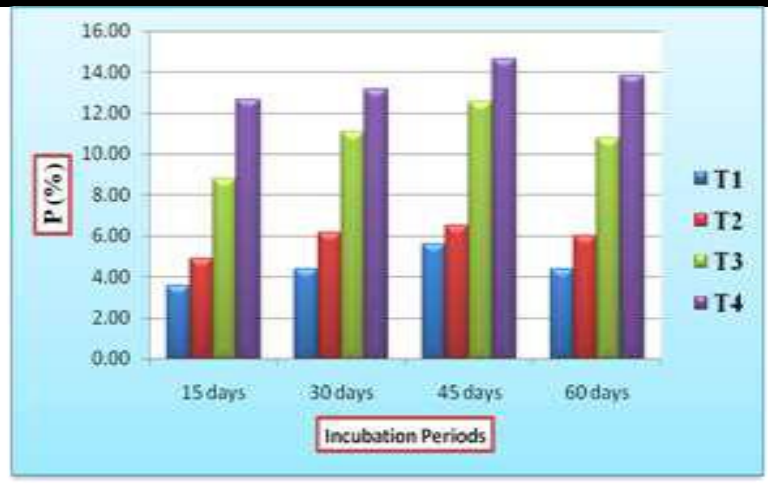

Fig.4: Effect of treatments on phosphorus content (\%)

\subsection{Potassium $(\%)$}

The application of organic matter caused significant differences in potassium content between all treatments and the control. Generally, at 45 days of incubation, potassium content was the highest. The control treatment T1 was the lowest (38.17 $\mathrm{mg} \mathrm{kg1-)}$ and treatment $\mathrm{T} 2$ (HA) was the highest (69.39 mg $\mathrm{kg} 1-)$. Comparing treatments $\mathrm{T} 3(\mathrm{HA}+\mathrm{ChM})$ and $\mathrm{T} 4(\mathrm{HA}+\mathrm{CoM})$, one can observe that the values of $\mathrm{K}$ content was $66.33 \mathrm{mg} \mathrm{kg} 1$ - in treatment $\mathrm{T} 3(\mathrm{HA}+\mathrm{ChM})$, while in $\mathrm{T} 4(\mathrm{HA}+\mathrm{CoM})$ it was $59.13 \mathrm{mg} \mathrm{kg} 1-$. But the treatment T3 $(\mathrm{HA}+\mathrm{ChM})$ was the best compared with others (Fig. 5). The addition of organic matter increased the availability of potassium content in soil due the release of potassium upon organic matter decomposition. Similar results were obtained by [21], who found that application of manure increase the soil potassium.

\subsection{Soil organic carbon (\%)}

The addition of organic material has a significant effect on soil organic matter content (SOM) during the incubation period. The soil organic matter content was highest in treatment T4 (HA + CoM) $(1.98 \%)$ and lowest in the control treatment $\mathrm{T} 1(1.25 \%)$. That is due to the addition of cow manure to soils can improve some soil properties such as organic matter content. Generally, the organic matter content ranged from 1.25\%, 1.89\%, 1.64\% and $1.98 \%$ for T1, T2 (HA), T3 (HA + ChM) and T4 (HA $+\mathrm{CoM}$ ) respectively (Fig. 6). It was observed in this study treatment T4 $(\mathrm{HA}+\mathrm{CoM})$ was the best treatment compared with others. That could be explained by the fact that cow manure is a source of organic carbon. Similar results were obtained by [22-23], who showed an increase in soil organic carbon with increased cow manure application. 


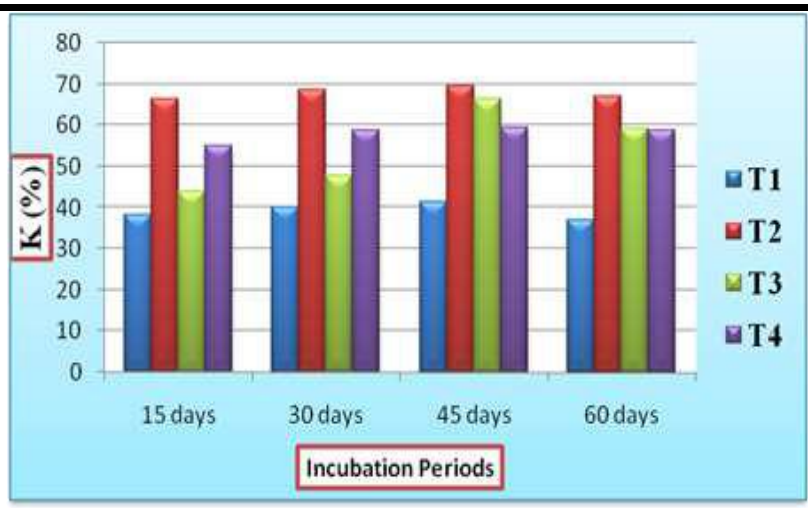

Fig.5: Effect of treatments on potassium content (\%)

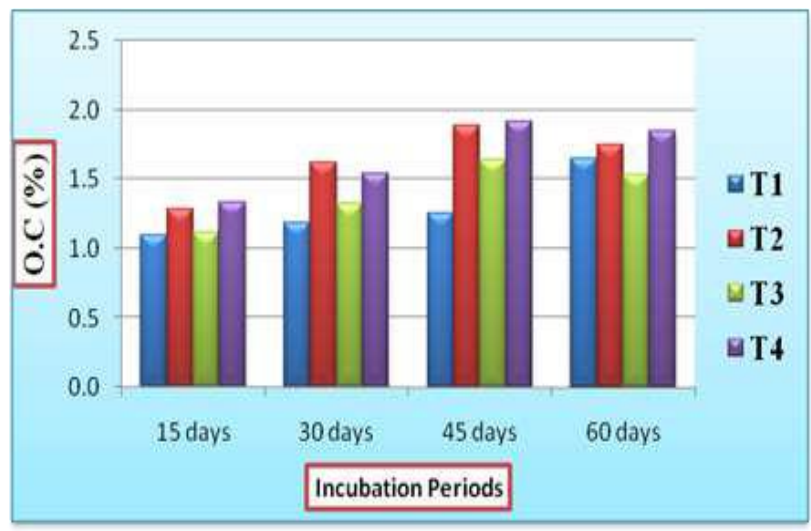

Fig. 6: Effect of treatments on soil organic matter content (SOM)

\subsection{Soil respiration $\left(\mathrm{CO}_{2}\right)$}

The results indicated that addition of organic material has an effect on $\mathrm{CO}_{2}$ emission throughout the incubation period. In general, statistical analysis showed that the highest carbon dioxide $\left(\mathrm{CO}_{2}\right)$ was at 45 days of incubation period and decreased by time. This is natural becuase of the decrease of the organic material and hence, the decrease of the decomposing orgnisms. The control treatment $\mathrm{T} 1$ was the lowest (114.54 $\left.\mathrm{mg} \mathrm{kg}^{-1}\right)$ and treatment $\mathrm{T} 4(\mathrm{HA}+\mathrm{CoM})$ was the highest $(178.56 \mathrm{mg}$ $\mathrm{kg}^{-1}$ ) (Fig. 7) because the decomposition of cow manure released more $\mathrm{CO}_{2}$ by soil microbes and that is an indicator of soil health (the level of microbial activity). These results were approximately in line with the findings of [24], who reported that application of manure can increase microbial populations by up to 1000 -fold.

Fig. 7: Effect of treatments on soil CO2 emission $\left(\mathrm{mg} \mathrm{kg}^{-1}\right)$

\section{CONCLUSION}

In general, the results of the laboratory incubation experiments indicated that application of organic matter had significant effect on soil biochemical properties and treatment 4 T4 (HA+ CoM) showed a significant superiority compared with other treatments.

\section{ACKNOWLEDGEMENTS}

Authors are thankful to staffs of the Department of Soil and Plant Nutrition, Faculty of Agriculture, Ankara University. Especially, Prof. Dr. Sadik USTA for valuable help and support.

\section{REFERENCES}

[1] Gomez-Brandon M, Fernandez-Delgado MJ, Domiguez J, Insam H (2013) Animal manures: recycling and management technologies. INTECH Open Sci. doi:10.5772/53454.

[2] Whalen, JK; Ch Chang; GW Clayton \& JP Carefoot. (2000). Cattle manure amendments can increase the pH of acid soils. Soil sci. Soc. Am. (J) 64: 962-966.

[3] Li-Xian, and; L Guo-Liang; T Shi-Hua; Gavin s \& H Zhao-Huan. (2007). Salinity of animal manure and potential risk of secondary soil salinization through successive manure application. Sci. Total Environ. 383: 106-114.

[4] Mohammad Fahramand, Hossein Moradi, Mohsen Noori, Alireza Sobhkhizi, Mohammad Adibian, Shila abdollahi and Khashayar Rigi (2014) Influence of humic acid on increase yield of plants and soil properties. Intl J Farm \& Alli Sci. Vol., 3 (3): 339341.

[5] Atiyeh RM, Lee S, Edwards CA, Arancon NQ and Metzger JD. (2002), the influence of humic acids derived from earthworm processed organic wastes on plant growth. Soil Ecology Laboratory, 105 Botany and Zoology Building, The Ohio State University, 1735 Neil Avenue, Columbus, OH 43210, USA.

[6] Liu M., Hu F., Chen X., Huang Q., Jiao J., and Zhang B., Li H. (2009). Organic amendments with reduced chemical fertilizer promote soil microbial development and nutrient availability in a subtropical paddy field: The influence of quantity, type and application time of organic amendments. Applied Soil Ecology, 42: 166-175.

[7] Saka, H.A., Azeez, J.O., Odedina, J.N. et al (2017). Dynamics of soil nitrogen availability indices in a sandy clay loam soil amended with animal manures. Int J Recycl Org Waste Agricult 6: 167. doi:10.1007/s40093-017-0165-7.

[8] Soil Survey Staff (2010), Keys to Soil Taxonomy. USDA-NRCS, Agricultural Handbook No. 436. (11th ed.) U.S. Government Printing Office, Washington, D.C. USA.

[9] Page, A. L.; Miller, R. H. and Ceaney, D. R. (1982). Methods of Soil analysis. Part 2. Chemical and Microbiological Properties, 2nd edition, American Society of Agronomy, Inc., Soil Science Society of (I) America, Inc., Wisconsin, USA. 
[10] AOAC, (2005). Official Methods of Analysis, 18th ed. Association of Official Analytical Chemists, Washington, DC, USA.

[11] Nelson, D.W and Sommers, L.E. (1996). Methods of Soil Analysis. Part 3. Chemical Methods. Soil Science Society of America Book Series no.5, pp. 961-1010.

[12] Pesis, E. and R. Ben-Arie, (1984). Involvement of acetaldehyde and ethanol accumulation during induced deastringency of persimmon fruits. J. Food Sci., 49: 896-899.

[13] Lurie, S. and E. Pesis, (1992). Effect of acetaldehyde and anaerobiosis as post-harvest treatment on the quality of peaches and nectarines. Post. Biol. \& Technol., 1: 317-326.

[14] SAS Institute SAS/STAT® 9.2 User's Guide. SAS Institute: Cary, NC 2008.

[15] Shah, R.U., Abid, M., Qayyum, M.F. (2015). Dynamics of chemical changes through production of various composts/vermicompost such as farm manure and sugar industry wastes. Int J Recycl Org Waste Agricult 4: 39. doi:10.1007/s40093-015-0083-5

[16] Horswill P, O'Sullivan O, Phoenix GK, Lee JA, Leake JR (2007). Base cation depletion, eutrophication and acidification of species-rich grasslands in response to long-term.

[17] Azeez, J.O. and Van Averbeke, W. (2012). Dynamics of Soil $\mathrm{pH}$ and Electrical Conductivity with the Application of Three Animal Manures. Communications in Soil Science and Plant Analysis, 43,865-874. http://dx.doi.org/10.1080/00103627509366539.

[18] Yadav, A., Gupta, R. \& Garg, V.K. (2013). Organic manure production from cow dung and biogas plant slurry by vermicomposting under field conditions. Int J Recycl Org Waste Agricult 2: 21. doi:10.1186/2251-7715-2-21.

[19] Ojeniyi, S.O. Akanni, D. A. and Awodum, M.A (2007). Effect of goat manure on some soil properties growth, yield and nutrient status of tomato. U. of K. J Agric. Sci. 15 (3) 396-406.

[20] Tandon, H.L.S., (2000). Fertilizer organic manures wastes and bio-fertilizers components of integrated plant fertilizer development and consultation organization 204-204, A Bhanot corner, 1-2 pamposh Enclave New Delhi., 1 10048. India.

[21] Cooper, S. R., Topliff, D. R., Freeman, D.W., Breazile, J. E. and Geisert, R. D. (2000). Effect of dietary cation-anion difference on mineral balance, serum osteocalcin concentration and growth in weanling horses. J Eq Vet Sci. 20:39.

[22] Elhadi, E.A., Mubarak, A.R. \& Rezig, F.A.M. (2016). Effects of organic amendments on sand dune fixation. Int J Recycl Org Waste Agricult 5: 1. doi:10.1007/s40093-015-0111-5.

[23] Eghball, B. (2002). Soil properties as influenced by phosphorus-and nitrogen-based manure and compost applications. Agronomy Journal 94, 128-135.

[24] Carter, J. (2002). Potatoes and manure: Researchers discover they do mix. Spudman, February 2002: 3233. 